\title{
Correction to: Non-vitamin K antagonist oral anticoagulants in patients with an increased risk of bleeding
}

\author{
Thomas Gremmel (D) - Alexander Niessner · Hans Domanovits · Martin Frossard · Gürkan Sengölge · \\ Barbara Steinlechner · Thomas Sycha $\cdot$ Michael Wolzt · Ingrid Pabinger
}

Published online: 22 February 2019

(C) The Author(s) 2019

\section{Correction to:}

Wien Klin Wochenschr 2018

https://doi.org/10.1007/s00508-018-1381-5

Unfortunately, the original version of this article contained two mistakes.

The text passage "It should be mentioned here that in the case of apixaban, dose adjustment is not based on GFR. A lower dosage of apixaban should be used if serum creatinine is $\geq 1.5 \mathrm{mg} / \mathrm{dl}(133 \mu \mathrm{mol} / \mathrm{l})$ and either one of the following criteria is fulfilled: age $\geq 80$ years or weight $\leq 60 \mathrm{~kg}$." is incorrect because GFR alone is a dose reduction criterion for apixaban in patients with NVAF if it falls below $30 \mathrm{ml} / \mathrm{min}$.

In addition the sentence "There are specific recommendations for dose reduction of dabigatran and apixaban 1 in patients $\geq 80$ years, but not for rivaroxaban and edoxaban" is incorrect. The correct sentence should be "There are specific recommendations for dose reduction of dabigatran and-only in NVAF-apixaban in patients $\geq 80$ years, but not for rivaroxaban and edoxaban."

We apologize for the mistakes.
The online version of the original article can be found under https://doi.org/10.1007/s00508-018-1381-5.

Prof. Dr. T. Gremmel, MD ( $\varangle)$ · Prof. Dr. A. Niessner, MD ( $\varangle)$ Department of Internal Medicine II, Medical University of Vienna, Währinger Gürtel 18-20, 1090 Vienna, Austria thomas.gremmel@meduniwien.ac.at; alexander.niessner@meduniwien.ac.at

Prof. Dr. T. Gremmel, MD

Department of Internal Medicine, Cardiology and Nephrology, Landesklinikum Wiener Neustadt, Wiener Neustadt, Austria

\section{H. Domanovits}

Department of Emergency Medicine, Medical University of Vienna, Vienna, Austria

\section{Frossard}

Department of Trauma Surgery, Medical University of Vienna, Vienna, Austria

\section{G. Sengölge}

Department of Internal Medicine III, Medical University of Vienna, Vienna, Austria

\section{B. Steinlechner}

Department of Anesthesia, Intensive Care Medicine and Pain Medicine, Medical University of Vienna, Vienna, Austria

T. Sycha

Department of Neurology, Medical University of Vienna, Vienna, Austria

\section{Wolzt}

Department of Clinical Pharmacology, Medical University of Vienna, Vienna, Austria

Prof. Dr. I. Pabinger, MD ( $\square)$

Department of Internal Medicine I, Medical University of Vienna, Währinger Gürtel 18-20, 1090 Vienna, Austria

ingrid.pabinger@meduniwien.ac.at 